\title{
Evidence-Based Nursing Setting and image
}

\author{
Mitzy Tannia Reichembach', Letícia Pontes"
}

\author{
'Nurse. PhD in History. Associate Professor in the Universidade Federal do Paraná. Full Member of the \\ University Board of the Universidade Federal do Paraná. Leader of the Technology and Innovation in Health \\ Research Group of the Universidade Federal do Paraná. Curitiba, Paraná, Brazil. \\ "Nurse. PhD in Education. Adjunct Professor in the Universidade Federal do Paraná. Vice Coordinator \\ of the Graduation Program in Professional Nursing of the Universidade Federal do Paraná, \\ Management 2017-2019. Curitiba, Paraná, Brazil.
}

\author{
How to cite this article: \\ Reichembach MT, Pontes L. Evidence-Based Nursing Setting and image. Rev Bras Enferm [Internet]. \\ 2018;71(6):2858-9. DOI: http://dx.doi.org/10.1590/0034-7167-2018710601
}

In the world, Evidence-Based Nursing (EBN) has carried out an intense statement of position, including determining health policies. But, in Brazil, still, it is a subject that requires greater discussion.

International policy recommends the training of leaders for the development and dissemination of knowledge with the aim of improving Nursing practice. At the last International Nursing Research Congress, held in Melbourne, Australia, in July of this year, the Society of Nursing, Sigma Theta Tau International, organizer of the event, promoted extensive debate and presentations of successful experiences and research on Evidence-Based Nursing as basis for professional Nursing practice.

EBN is characterized as the integration of the best available evidence, Nursing competence and values and preferences of the individuals, families and communities served. This presupposes that the nurse is able to exercise his judgment, planning and provide care that take into account cultural and personal values and preferences.

Demographic changes, life expectancy, increased prevalence of chronic diseases, prevention with a focus on well-being and health policies, are factors that affect overall health. Since 2015, the World Health Organization has set goals for the sustainable development of population health, with the attributes established being accessibility, acceptability and adaptability.

Accessibility refers mainly to the recommendations of the WCAG ${ }^{(1)}$ (World Content Accessibility Guide) and, in the case of the Government of Brazil, the e-MAG (Accessibility Model in Electronic Government). E-MAG is aligned with international recommendations, but sets standards for accessible behavior for government sites. Acceptability, in Evidence-Based Nursing, is an essential attribute of an information system and is characterized by the adherence of health professionals to the guidelines, contributing to adaptability to different circumstances.

It is considered that health systems should be resilient because they face significant limitations that are clearly stated, such as insufficient numbers of skilled health professionals, available medicines below the needs, fragile information systems, inadequate infrastructure and scarce public funding.

Resilience is characterized as the ability of a system to adjust its activities to maintain its basic functionality, even when environmental challenges, failures and changes occur ${ }^{(2)}$. The resilience of the health system refers to the ability to absorb disruption, respond and recover with the timely delivery of the necessary services. That is, the capacity of actors, health institutions, and the population to prepare themselves to respond effectively to crises while maintaining core functions ${ }^{(2)}$. EBN responds quickly to the resilience attribute, as it establishes a current and future voice and vision of Nursing in the search to promote global health, while at the same time strengthening professional roles.

It is understood that the greatest challenge for the training of nurses in Evidence-Based Nursing is related to their basic training and the valuation of the profession, as well as in-service education programs, focusing on practice based on the best evidence.

The impact of EBN practice is on the impact on clinical outcomes, on the reduction of adverse events, on patient mortality and hospital stay days, and consequently on cost reductions. In addition, EBN streamlines waiting times for other patients. 
Since the basic training, nurses must have strategic guidelines for the strengthening and development of evidencebased actions, providing the practice of advanced Nursing, which guarantees quality and safe working conditions.

Thus, it is necessary to strengthen and align curricula, which meet the knowledge needs to act effectively with the patient/community, using the best available evidence, taking into account health policies.

This recommendation can ensure the practice of advanced Nursing, adopting the best available evidence for Nursing care actions, appropriate to individuals, groups and populations with varied needs.

\section{REFERENCES}

1. World Health Organization-WHO. Strengthening essential public health functions in support of the achievement of universal health coverage [Internet]. Geneva: WHO; 2016[cited 2016 Mar 18]. Available from: http://apps. who.int/gb/ebwha/pdf_files/EB138/B138_CONF6-en.pdf

2. Gao J, Barzel B, Barabási AL. Universal resilience patterns in complex networks. Nature [Internet]. 2016 [cited 2016 Mar 18];530(7590):307-12. Available from: http://www.nature.com/nature/journal/v530/n7590/abs/nature16948. html CD55/9 13 